\title{
Use of Probemix and OmniProbe biotinylated cDNA probes for detecting HPV infection in biopsy specimens from the genital tract
}

\author{
I Zehbe, E Rylander, A Strand, E Wilander
}

\begin{abstract}
Aims-To compare two commercially available pan probes for the identification of human papillomavirus (HPV) DNA expression in histological sections and to type the HPV positive cases.

Methods-97 formalin fixed, paraffin wax embedded biopsy specimens from the genital tract were tested for HPV positivity with in situ hybridisation using biotinylated cDNA pan probes-Probemix (Enzo) and OmniProbe (Digene). The HPV positive cases were further tested with HPV types 6/11, 16/18, and $31 / 33 / 35 / 51$, and the HPV type was related to the histological diagnosis. Formalin fixed, HeLa cells (10-50 HPV 18 copies per cell) and SiHa cells (1-2 HPV 16 copies per cell) were used as reference cell lines.

Results-32\% of the specimens gave positive nucleic signals with both Probemix and OmniProbe. Of these, $84 \%$ could be further characterised with regard to HPV types 6/11, 16/18, and 31/33/35/51; 4\% of all cases were positive with either Probemix or OmniProbe. The concordance of these probes was high, $96 \%$ altogether. HeLa cells stained positive but SiHa cells did not.

Conclusion-There is no difference between Probemix and OmniProbe for the general detection of HPV. The mean detection limit of these probes is about 20 copies a cell.
\end{abstract}

(F Clin Pathol 1993;46:437-440)

Human papillomavirus (HPV) is associated with anogenital tract lesions. Although certain HPV types (such as 6/11) occur mainly in benign lesions such as condyloma acuminatum, others $(16 / 18)$ increase the risk of developing anogenital malignancies. ${ }^{1-4}$

In situ hybridisation with biotinylated cDNA probes is a frequently used molecular hybridisation method that permits the determination of HPV type in relation to the morphological appearance of the lesion. ${ }^{5-7}$ A cDNA pan probe for HPV detection is an adjunct to the histopathological diagnosis and can be used for screening. Tissues positive with this probe may be assayed subsequently using type specific probes for HPV.

Methods

Eighty patients, aged between 15 and 51 years, with HPV suspect or manifest lesions were studied. Ninety seven formalin fixed, paraffin wax embedded tissue samples from the genital tract were processed for histopathological diagnosis and in an additional sequence tested for HPV positivity with in situ hybridisation using biotinylated cDNA pan probes (Enzo Diagnostics Inc, New York, Beltsville, USA (Probemix) and Digene, Maryland, USA (OmniProbe)). Both probes use a mixture of HPV specific probes formulated to detect most HPV types associated with anogenital lesions. With Probemix no further details are known as to what types exactly are covered, but OmniProbe detects HPV types $6,11,16,18,31,33,35,42,43$, 44, 45, 51, 52 and 56. Enzo Diagnostics offers Probemix as a complete kit including reagents for alkaline phosphatase detection and HPV positive biopsy controls. OmniProbe, however, may be purchased with positive DNA controls and negative plasmid controls only. Both control systems were applied according to the manufacturers' recommendations and found to work satisfactorily. To assess the sensitivity of the various probes applied, we used formalin fixed $\mathrm{HeLa}$ cells (10-50 HPV 18 copies a cell), a gift from Dr Eva Rupp, The Ludwig Cancer Institute, Uppsala, Sweden and $\mathrm{SiHa}$ cells (1-2 HPV 16 copies a cell), HTB 35, ATCC. Biopsy specimens that stained positive with either of these two general HPV probes were also typed for HPV 6/11 (Enzo and Digene), 16/18 (Enzo and Digene), 18 (Enzo), 31/33/51 (Enzo) and 31/33/35 (Digene). HPV types $42,43,44,45,52$ and 56 are not yet commercially available.

Briefly, 4-6 $\mu \mathrm{m}$ sections on organosilane coated slides were treated with proteinase $K$ (P-0390; Sigma) at a concentration of $0.1 \mathrm{mg} / \mathrm{ml}$ SSPE buffer for 15 minutes at $37^{\circ} \mathrm{C}$ and the endogenous peroxidase activity blocked in aqueous $3 \% \mathrm{H}_{2} \mathrm{O}_{2}$. Slides were dehydrated in $99 \%$ ethanol, air dried, and denaturated for 5 minutes at $94^{\circ} \mathrm{C}$. Hybridisation was carried out in a humid chamber overnight (pan probes) and for two hours (type specific probes to prevent cross-hybridisation) at $37^{\circ} \mathrm{C}$. Posthybridisation was performed in $50 \%$ formamid $/ 2 \times$ SSPE (final concentration) for 10 minutes at $37^{\circ} \mathrm{C}$, followed by enzymatic detection with biotinylated horseradish peroxidase bound to streptavidin (K 377 A-B; Dakopatts) 1 in 100 for 30 minutes at $37^{\circ} \mathrm{C}$ and visualisation with diaminobenzidine (DAB)- $\mathrm{H}_{2} \mathrm{O}_{2}$. The DAB- 
Table 1 HPV negative and HPV positive cases stained with both pan probes in relation to histological diagnosis

\begin{tabular}{llll}
\hline $\begin{array}{l}\text { Histological } \\
\text { diagnosis }\end{array}$ & $\begin{array}{l}\text { HPV negative } \\
\text { biopsies }\end{array}$ & $\begin{array}{l}\text { HPV positive } \\
\text { biopsies }\end{array}$ & Total \\
\hline Negative findings & 41 & 0 & 41 \\
Hyperplasia & 6 & 1 & 7 \\
Condyloma & & & \\
$\quad$ acuminatum & 0 & 9 & 9 \\
Flat condyloma & 10 & 6 & 16 \\
SIL I & 0 & 2 & 2 \\
SIL II & 2 & 9 & 12 \\
SIL III & 7 & 6 & 12 \\
Total & 66 & 33 & 99 \\
\hline
\end{tabular}

$\mathrm{H}_{2} \mathrm{O}_{2}$ detection system was better than that using alkaline phosphatase. Finally, the slides were counterstained in Mayer's haematoxylin, rinsed in graded ethanols and xylene, and placed on to coverslips. ${ }^{8} \mathrm{HeLa}$ and $\mathrm{SiHa}$ cells were treated in exactly the same manner.

The following classification was used for the morphological diagnosis: 1 normal squamous epithelium and inflammatory or reactive changes; 2 hyperplasia, referring to a thickening of the squamous mucosa, but lacking koilocytosis and nuclear atypia; three condyloma acuminatum and flat condyloma. Four SIL (squamous intraepithelial lesion) I-III with or without koilocytosis corresponding to mild, moderate, and severe dysplasia or carcinoma in situ (CIS).

\section{Results}

PAN-PROBES

Of the 97 biopsy specimens tested, 27 showed a positive reaction for HPV with both Probemix and OmniProbe. Two sections were also positive only with Probemix and two only with OmniProbe. The total number of positive specimens with both pan probes was $31(32 \%)$. The concordance of these probes was high, $96 \%$ altogether. The sensitivity of both probes was considered to be 10-50 copies a cell because formalin fixed HeLa cells stained positive with either pan probe whereas $\mathrm{SiHa}$ cells stained negative. Of the 31 positive biopsy specimens 26 (84\%) could also be identified for HPV types $6 / 11$, $16 / 18,18$ and $31 / 33 / 35 / 51$. Of $66 \mathrm{HPV}$ negative biopsy specimens 41 were categorised according to group 1 . The remaining HPV negative biopsy specimens were hyperplasias $(n=6)$, flat condylomas $(n=10)$, SIL II with koilocytosis $(n=1)$, SIL II without koilocytosis $(n=1)$ and SIL III without koilocytosis (n $=7$ ). Results are summarised in tables 1 and 2.

TYPE SPECIFIC HPV PROBES AND MORPHOLOGY The type specific probes differed only in biopsy specimens with HPV positivity for $31 / 33 / 35 / 51$ (cases $11,15,26$ and 28). The reason for this is most probably the fact that Enzo combines HPV types 31/33/51 and Digene HPV types 31/33/35. HeLa cells showed an equal staining intensity with the type specific probes for $16 / 18$ (Enzo and Digene) and 18 (Enzo) compared with the pan probes. SiHa cells stained negative with the type specific probes 16/18 (Enzo and Digene) as was seen with both pan probes.

HPV types $6 / 11$ were found in lesions morphologically categorised as condyloma acuminatum $(n=9)$, hyperplasia $(n=1)$, and flat condyloma $(n=1)$. HPV 16 (and negative for HPV 18) was seen in four cases: flat

Table 2 HPV positive cases and interrelation between morphology and HPV types in individual biopsy specimens

\begin{tabular}{|c|c|c|c|c|c|c|c|}
\hline \multirow[b]{2}{*}{ Case No } & \multirow{2}{*}{$\begin{array}{l}\text { Age } \\
(y r)\end{array}$} & \multirow{2}{*}{$\begin{array}{l}\text { Biopsy } \\
\text { site }\end{array}$} & \multirow{2}{*}{$\begin{array}{l}\text { Histological } \\
\text { diagnosis }\end{array}$} & \multicolumn{2}{|c|}{ Pan probes } & \multicolumn{2}{|c|}{ HPV typing } \\
\hline & & & & ENZO & Digene & ENZO & Digene \\
\hline \multirow[t]{2}{*}{1} & 51 & vagina & SIL III wo k & + & + & - & $31 / 33 / 35$ \\
\hline & & vulva & SIL II w k & + & + & - & $31 / 33 / 35$ \\
\hline 2 & 15 & portio & SIL II w k & + & + & $31 / 33 / 51$ & $31 / 33 / 35$ \\
\hline \multirow[t]{2}{*}{3} & 20 & portio* & Flat condyloma & + & + & & $16 / 18$ \\
\hline & & & Condyloma acuminatum & + & + & $6 / 11$ & $6 / 11$ \\
\hline 4 & 21 & vulva & Flat condyloma & + & + & 16 & $16 / 18$ \\
\hline 5 & 42 & portio & Condyloma acuminatum & + & + & $6 / 11$ & $6 / 11$. \\
\hline 6 & 28 & portio & SIL II w k & + & + & 16 & $16 / 18$ \\
\hline 7 & 22 & vagina & Hyperplasia & + & + & $6 / 11$ & $6 / 11$ \\
\hline 8 & 20 & portio & Flat condyloma & + & + & $6 / 11$ & $6 / 11$ \\
\hline 9 & 20 & portio & Condyloma acuminatum & + & + & $6 / 11$ & $6 / 11$ \\
\hline 10 & 22 & portio & Condyloma acuminatum & + & - & $6 / 11$ & $6 / 11$ \\
\hline 11 & 32 & portio & SII III wo $k$ & - & + & $31 / 33 / 51$ & - \\
\hline 12 & 44 & cervix & SIL III wo $\mathrm{k}$ & + & + & - & - \\
\hline \multirow[t]{2}{*}{13} & 29 & portio* & Flat condyloma/ & + & + & $31 / 33 / 51$ & $31 / 3.3 / 35$ \\
\hline & & & Condyloma acuminatum & + & + & $6 / 11$ & $6 / 11$ \\
\hline 14 & 23 & portio & SIL II $\mathrm{w} k$ & + & + & $31 / 33 / 51$ & $31 / 33 / 35$ \\
\hline 15 & 21 & portio & SIL II w k & + & + & $31 / 33 / 51$ & - \\
\hline 16 & 31 & vagina & Condyloma acuminatum & + & + & $6 / 11$ & $6 / 11$ \\
\hline 17 & 29 & portio & SIL II w k & + & + & 16 & $16 / 18$ \\
\hline 18 & 21 & portio & Condyloma acuminatum & + & + & $6 / 11$ & $6 / 11$ \\
\hline \multirow[t]{2}{*}{19} & 20 & portio & SIL II wo $k$ & + & + & 18 & $16 / 18$ \\
\hline & & portio & SIL II w k & - & + & - & - \\
\hline 20 & 26 & portio & Condyloma acuminatum & + & + & $6 / 11$ & $6 / 11$ \\
\hline 21 & 45 & portio & SIL I w k & + & - & - & - \\
\hline 22 & 26 & penis & SIL I wo $k$ & + & + & $31 / 33 / 51$ & $31 / 33 / 35$ \\
\hline 23 & 34 & portio & SIL II w k & + & + & $31 / 33 / 51$ & $31 / 33 / 35$ \\
\hline 24 & 19 & portio & Condyloma acuminatum & + & + & $6 / 11$ & $6 / 11$ \\
\hline 25 & 34 & portio & SIL III wo $k$ & + & + & 16 & $16 / 18$ \\
\hline 26 & 32 & portio & SII II wo $k$ & + & + & $31 / 33 / 51$ & - \\
\hline 27 & 23 & penis & Flat condyloma & + & + & - & - \\
\hline 28 & 46 & portio & Flat condyloma & + & + & - & $31 / 33 / 35$ \\
\hline 29 & 40 & portio & SIL III wo $k$ & + & + & 18 & $16 / 18$ \\
\hline
\end{tabular}

«Two HPV types were identified in these patients in different areas of the epithelium. SIL, squamous intraepithelial lesion; SIL w k, squamous intraepithelial lesion with koilocytosis; SIL wo k, squamous lesion without koilocytosis. The biopsy specimens of tests $4,7,21$, and 27 were also negative for HPV DNA 


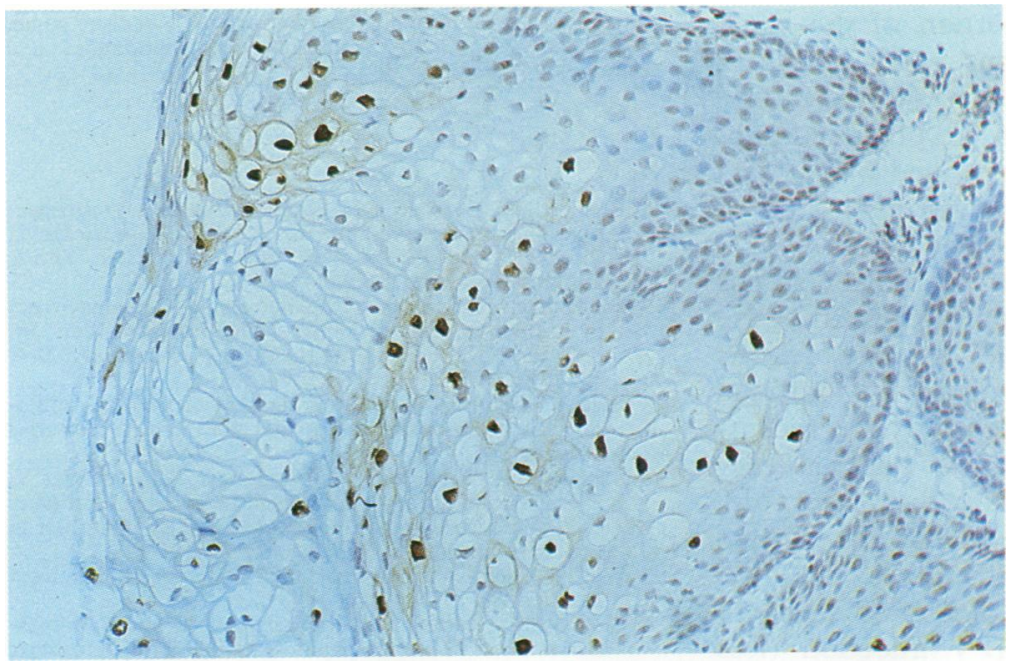

Figure 1 Portio biopsy specimen with condyloma acuminatum positive for HPV 6/11 (Digene); detected with $\mathrm{DAB}-\mathrm{H}_{2} \mathrm{O}_{2}$.

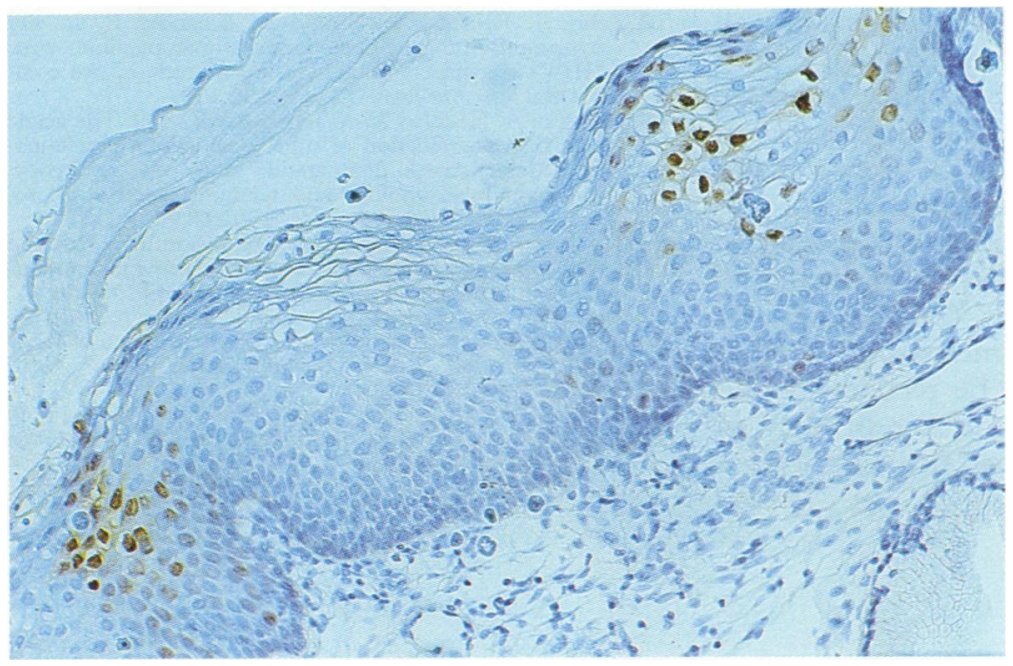

Figure $2 A$ different part of the epithelium representing flat condyloma positive for HPV 18 (ENZO); detected with $\mathrm{DAB}-\mathrm{H}_{2} \mathrm{O}_{2}$.

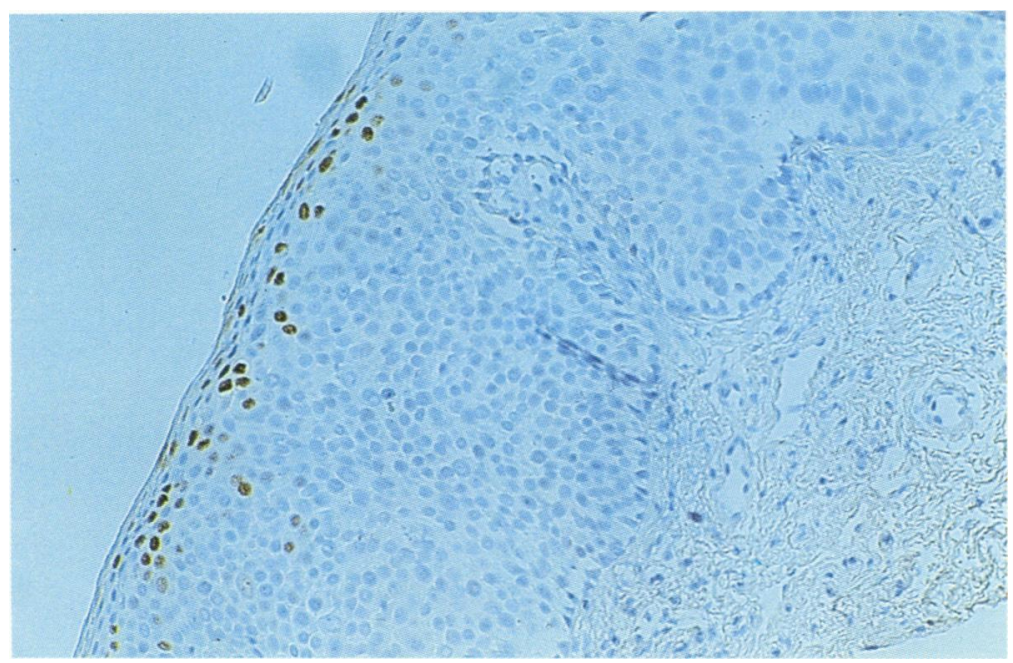

Figure 3 A penile SIL I lesion without koilocytosis positive with HPV 31/33/35 (Digene); detected with $\mathrm{DAB}-\mathrm{H}_{2} \mathrm{O}_{2}$.

condyloma ( $\mathrm{n}=1$ ), SIL II with koilocytosis $(n=2)$, and SIL III without koilocytosis $(n=1)$. HPV 18 was found in three cases. One of these was also positive for HPV types $6 / 11$ in a different area of the epithelium. HPV 6/11 was present in a condyloma acumi- natum and HPV 18 in an area with flat condyloma (case 3) (figs 1 and 2). The two other positive HPV 18 biopsy specimens were seen in an SIL II and SIL III lesion without koilocytosis. Most of the biopsy specimens, altogether 11, stained positive with $31 / 33 / 35 / 51$. One of those turned out to be double positive with HPV types 6/11 in epithelium showing condyloma acuminatum and with HPV types $31 / 33 / 35 / 51$ in epithelium with flat condyloma (case 13). The others were diagnosed as follows: flat condyloma ( $\mathrm{n}$ $=1$ ), SIL I without koilocytosis $(n=1$ ) (fig 3), SIL II with koilocytosis $(n=4)$, SIL II without koilocytosis $(n=1)$ and SIL III without koilocytosis $(n=3)$. Biopsy specimens with negative findings such as normal mucosa and inflammatory changes were all HPV negative.

All controls used were satisfactory. Low risk HPV types 6/11 were more often found in epithelium with condyloma acuminatum than in squamous intraepithelial lesions of varying severity. Flat condylomas showed mainly positive signals of either high risk HPV types $16 / 18$ or medium risk HPV types 31/33/ $35 / 51$. The fact that some specimens were reactive with the pan probes but negative with the type specific probes, may indicate either the presence of yet uncharacterised HPV types or HPV types 42-45, 52, and 56 included in Digene's OmniProbe.

\section{Discussion}

Evaluation of methods to detect possible HPV in biopsy specimens is frequently requested as a complement to ordinary histopathological diagnosis. The purpose is not only to demonstrate the presence of HPV DNA in general, but rather to obtain information of the specific HPV types expressed. This is of variable prospective clinical importance. Because a considerable number of the known HPV types may invade the genital mucosa, several sequential sections from each individual biopsy specimen are needed to analyse all the different HPV types. For this reason a pan probe represents a technical improvement. Pan probes can be applied for the screening of biopsy specimens with regard to HPV DNA expression. Sections with a positive HPV DNA reaction are tested with different type specific cDNA probes in a second sequence, while in negative specimens no further hybridisation tests are necessary, thus reducing workload and saving costs. This applied to $68 \%$ of the biopsy specimens in our study.

Probemix and OmniProbe are of the same diagnostic value for the general detection of HPV. The sensitivity of the pan probes is about $10-50$ copies a cell as formalin fixed HeLa cells showed positive signals in the present study. Furthermore, HeLa cells had the same staining intensity with the pan as well as the HPV type specific 18 probe. This indicates that specimens that are negative with the pan probes are also unreactive with the type specific probes. 
A relatively high proportion of the squamous intraepithelial lesions expressed HPV types $31 / 33 / 35 / 51$ in the present study. This discrepancy with respect to previous published findings may be explained by the fact that these HPV types have not been studied as systematically as HPV types $16 / 18$.

A considerable number of our specimens were HPV negative, despite the fact that the clinician suspected HPV positive lesions from the presence of distinctly outlined acetowhite areas of the mucosa. It was recently suggested that acetowhite patches may sometimes be associated with other viral, bacterial, or fungal infections rather than HPV alone. ${ }^{9}$

In situ hybridisation does not seem to indicate low intensity HPV infection (less than 20 copies a cell) and for that reason, tissues harbouring only a few HPV DNA copies will not be within the detection limit. Among these may be latent infections as well as advanced squamous intraepithelial lesions and invasive cancer. ${ }^{410}$ More sensitive methods for HPV identification have been presented, however, which, like in situ hybridisation, allow tissue morphology to be present for histopathological diagnosis. Among these new methods, the in situ polymerase chain reaction (PCR) appears promising. ${ }^{11-12}$ Using this method, 1-2 copies of HPV DNA a cell can be recognised and the genital changes and the role of HPV in their pathogenesis examined further.
This study was supported by grants from the Swedish Cancer Foundation (CaF), the Lion's Cancer Foundation, and Selander's Foundation.

1 Broker TR, Botchan MT. Papillomaviruses-retrospectives and prospectives. In: Botchan MT, Grodzicker T, Sharp P, eds. Cancer cells New York: Cold Spring Harbor Laboratory, 1986:17-36.

2 zur Hausen H, Schneider A. The role of papillomaviruse in human anogenital cancer. The Papovaviridae. In: Salzman NP, Howley P, eds. The papillomaviruses. New York: Plenum Press, 1987:245-63.

3 Reid R. The biology and significance of human papillomavirus infections in the genital tract. Yale $\mathcal{f}$ Biol Med 1988;61:307.

4 Schneider A, Meinhardt G, Kirchmayr R, Schneider V. Prevalence of human papillomavirus genomes in tissues frevalence of human papilomavirus genomes in tissues from the lower genital tract as detected by molec

5 Warford A, In situ hybridisation: a new tool in pathology. Med Lab Sci 1988;45:381.

6 Nuovo GJ, Friedman D, Richart RM. In situ hybridization analysis of human papillomavirus DNA segregation patterns in lesions of the female genital tract. Gynecol Oncol 1990;36:256.

7 Unger ER, Hammer ML, Chenggis ML. Comparison of ${ }^{35} \mathrm{~S}$ and biotin as labels for in situ hybridization: Use of an HPV model system. F Histochem Cytochem 1991;39:145.

8 Zehbe I, Rylander E, Strand A, Wilander E. In situ hybridization for the detection of human papillomavirus (HPV) in gynaecological biopsies. A study of two com(HPV) in gynaecological biopsies. A study
mercial kits. Anticancer Res 1992;12:1383.

9 Wikstöm A, Hedblad M-A, Johansson B, et al. The acetic acid test in evaluation of subclinical genital papillomavirus infection: A comparative study on penoscopy, histopathology, virology and scanning electron microscopy findings. Genitourin Med 1992;68:90

10 Nuovo GJ. A comparison of slot blot, Southern blot and in situ hybridisation analysis for human papillomavirus DNA in genital tract lesions. Obstet Gynecol 1989;74:74.

11 Nuovo GJ, Gallery F, MacConnell P, Becker J, Bloch W. An improved technique for the in situ detection of DNA after polymerase chain reaction amplification. $A m \mathcal{F}$ Pathol 1991;139:1239.

12 Nuovo GJ, Margiotta M, MacConnell P, Becker J. Rapid in situ detection of PCR-amplified HIV-1 DNA. Diagn Mol Pathost (in press). 